\title{
Differences in Rape Acknowledgement and Mental Health Outcomes across Transgender, Non-binary, and Cisgender Bisexual Youth
}

\author{
RaeAnn E. Anderson \\ University of North Dakota, raeann.anderson@UND.edu \\ Lesley A. Tarasoff \\ Nicole VanKim \\ Corey Flanders
}

\section{How does access to this work benefit you? Let us know!}

Follow this and additional works at: https://commons.und.edu/psych-fac

Part of the Psychology Commons

\section{Recommended Citation}

RaeAnn E. Anderson, Lesley A. Tarasoff, Nicole VanKim, et al.. "Differences in Rape Acknowledgement and Mental Health Outcomes across Transgender, Non-binary, and Cisgender Bisexual Youth" (2019). Psychology Faculty Publications. 7.

https://commons.und.edu/psych-fac/7

This Article is brought to you for free and open access by the Department of Psychology at UND Scholarly Commons. It has been accepted for inclusion in Psychology Faculty Publications by an authorized administrator of UND Scholarly Commons. For more information, please contact und.commons@library.und.edu. 
Differences in Rape Acknowledgement and Mental Health Outcomes across Transgender, Nonbinary, and Cisgender Bisexual Youth

RaeAnn E. Anderson ${ }^{1,2^{*}}$, Lesley A. Tarasoff ${ }^{3,4}$, Nicole VanKim ${ }^{5}$, \& Corey Flanders ${ }^{6}$

${ }^{1}$ Psychological Sciences, Kent State University

${ }^{2}$ Psychology, University of North Dakota

${ }^{3}$ Interdisciplinary Centre for Health \& Society, University of Toronto Scarborough

${ }^{4}$ Centre for Addiction and Mental Health

${ }^{5}$ Department of Biostatistics and Epidemiology, School of Public Health and Health Sciences, University of Massachusetts Amherst

${ }^{6}$ Department of Psychology and Education, Mount Holyoke College

*corresponding author: raeann.anderson@und.edu, 701-777-6824, fax: 701-777-3454, 2000

Columbia Hall, Grand Forks, ND, 58202

Acknowledgments: Thank you to the participants who shared their experiences with us. 


\begin{abstract}
Objective: The purpose of this study was to document the rates of rape acknowledgment (labeling rape as rape rather than using a minimizing label), and the corresponding mental health correlates using the minority stress framework in a unique and vulnerable sample: racially diverse sexual and gender minority young adults.
\end{abstract}

Method: Participants were 245 young adults who identified their sexual orientation as under the bisexual umbrella. A total of 159 of these participants (65.2\%) identified their gender identity as non-binary. All participants completed a series of online questionnaires regarding their sexual victimization history, mental health outcomes (depression, anxiety, and posttraumatic stress disorder: PTSD), and constructs relevant to minority stress theory (level of outness, internalized bisexual negativity, connection to LGBTQ community).

Results: Rape acknowledgment was significantly greater among gender non-binary participants (79.9\%) than among trans and cisgender male participants (17.9\%). Lack of rape acknowledgment was associated with increased anxiety, depression, and PTSD. Outness was significantly associated with greater rape acknowledgment.

Conclusions: In spite of the highly increased vulnerability for sexual violence among sexual and gender minorities, very little is understood about the mechanisms of this increased vulnerability nor their unique needs for recovery. The results of this study strongly suggest the importance of a minority stress framework for understanding this increased vulnerability and for designing sexual violence prevention and recovery interventions for sexual and gender minority populations.

Keywords: rape, PTSD, bisexual, gender identity, sexual minority 
Differences in Rape Acknowledgement and Mental Health Outcomes across Transgender, Nonbinary, and Cisgender Bisexual Youth

Rape is the experience of sex without consent by means of incapacitation (alcohol or other substances), threats of physical force, or physical force (Basile, Smith, Breiding, Black, \& Mahendra, 2014). Rape is a form of interpersonal violence, a type of trauma that is more likely to cause posttraumatic stress disorder (PTSD) than other civilian traumas (e.g., car accidents, Breslau et al., 1998). Rape is a common traumatic experience; epidemiological data indicates that $20 \%$ of American women will experience rape in their lifetimes, and most will occur before the age of 25 (Black et al., 2011). Sexual and gender minority (SGM) people experience increased vulnerability for rape and other forms of sexual violence (e.g., any sexual experience without consent; Griner et al., 2017; Rothman, Exner, \& Baughman, 2011) in comparison to their cisgender (non-trans) and heterosexual peers. Gender minorities (such as trans people, or people who identify with a gender other than that which they were assigned at birth, and nonbinary people, or those who do not identify with exclusive binary categories of male/female) are more vulnerable to sexual violence, though little research has examined this in relationship to specific gender minority identities. The 2015 U.S. Transgender Survey surveyed over 27,000 gender minority people, and found that $47 \%$ of respondents reported a lifetime history of sexual assault. Within the sample, people who identified as non-binary reported greater vulnerability for lifetime sexual violence (55\%) than those who identified with a binary trans identity (44\%, James et al., 2016). Other research estimates that up to 50\% of trans people experience sexual violence of some type (Stotzer, 2009) and most trans women worry about their physical safety in sexual situations (Bauer \& Hammond, 2015). People who identify as sexual minorities (i.e., gay, lesbian, bisexual and other non-heterosexual identities) are also at increased vulnerability 
(Rothman, Exner, \& Baughman, 2011; Black et al., 2011), with bisexual women reporting the greatest vulnerability. Epidemiological estimates indicate the lifetime prevalence of rape is $46.1 \%$ among bisexual women, compared to $13.1 \%$ of lesbian and $17.4 \%$ of heterosexual women, respectively (Walters, Chen, \& Breiding, 2013). The goal of this study was to examine rape acknowledgment among non-binary, transgender, and cisgender bisexual young people, as well as how rape acknowledgement among non-binary participants relates to mental health outcomes using a minority stress theory framework (Meyer, 2003). The results of this research may inform sexual violence prevention programs and treatment interventions for SGM people.

\section{Rape Acknowledgment and Mental Health Outcomes}

One construct of clinical importance to facilitating recovery after rape is rape acknowledgment. Rape acknowledgment refers to labeling a rape experience as such, rather than using other terms that minimize the severity of this event (for example, "miscommunication"; Littleton, Rhatigan, \& Axsom, 2007). Most rape survivors do not label their experiences as rape. Meta-analyses estimate that, on average, $60 \%$ of rape survivors are what the literature terms ‘unacknowledged victims’ (Wilson \& Miller, 2016). Unacknowledged rape is related to many clinical outcomes including depressive symptoms and vulnerability for repeated sexual victimization (Littleton, Axsom, \& Grills-Taquechel, 2009).

Rape acknowledgment likely represents both a consequence of rape and a mechanism of vulnerability for repeated victimization. Lack of acknowledgment (i.e., unacknowledged victimization) is associated with an increase in many negative mental health outcomes such as greater depressive symptoms, anxiety symptoms, and vulnerability for repeated sexual victimization (Hammond \& Calhoun, 2007; Littleton, Breitkopf, \& Berenson, 2008; Littleton et al., 2009; Soler-Baillo, Marx, \& Sloan, 2005). However, rape acknowledgement is associated 
with an increase in PTSD symptoms (Littleton et al., 2009; Littleton \& Henderson, 2009), particularly intrusion and avoidance symptoms (Wilson \& Scarpa, 2017), as well as avoidant coping (Littleton, Axsom, Breitkopf, \& Berenson, 2006). Other research shows acknowledgment associated with fewer emotional problems and better adjustment (Botta \& Pingree, 1997).

Thus, the mental health consequences associated with rape acknowledgment are varied and likely related to multiple factors including the characteristics of the assault, as well as characteristics of the individual and their environment. For example, one recent study of college women demonstrated that the relationship between rape acknowledgment and mental health outcomes is moderated by rape myth acceptance, that is, prejudiced, stereotyped beliefs about rape (Wilson, Newins, \& White, 2017). It may be that acknowledgment, while possibly painful and associated with PTSD symptoms, facilitates eventual recovery, as one is unlikely to process the painful emotions associated with rape while simultaneously denying it was a serious event. Rape acknowledgment may act as a mechanism to trigger coping (both adaptive and maladaptive), facilitating further coping and recovery for some.

\section{Sexual Violence and Sexual and Gender Minorities}

People who identify as sexual minorities, especially people who are bisexual, experience increased vulnerability for experiencing sexual violence (Balsam, Rothblum, \& Beauchaine, 2005; Walters et al., 2013). What causes this increased vulnerability is unclear; yet recent research suggests that bisexual-specific stigma and discrimination play a role (Flanders, Anderson, Tarasoff, \& Robinson, 2019). Further, little is known about how the process of coping and recovery after sexual victimization may be different for sexual minority people. Research has found that among community-residing bisexual women, sexual assault is associated with 
higher levels of PTSD symptoms and problem drinking in contrast to heterosexual and lesbian women (Sigurvinsdottir \& Ullman, 2015).

Trans and non-binary people are at increased vulnerability for all forms of sexual violence (Griner et al., 2017; Rothman et al., 2011; Stotzer, 2009). Indeed, in a study of college students, trans and non-binary people experienced sexual violence at a rate 2-3 times higher than their cisgender peers (Murchison, Boyd, \& Pachankis, 2016). Despite this, relatively little is known about their sexual victimization experiences or the rape-related mental health consequences of trans and non-binary people. In fact, we were unable to locate any literature regarding rape acknowledgment in either population.

Considering sexual orientation, cisgender sexual minority college men reported nearly 5 times higher rates of rape acknowledgment than their heterosexual peers (22.7\% vs. $4.3 \%$, Anderson, Wandrey, Klossner, Cahill, \& Delahanty, 2017). In addition to sexual orientation differences in rape acknowledgment, there are gender differences in rape acknowledgement. Available estimates from prior literature indicate cisgender heterosexual women are more likely to acknowledge their rape experiences than cisgender heterosexual men: $40 \%$ of women in Wilson et al. (2016) versus 4\% of heterosexual men in Anderson et al. (2017) and 24\% of men in Artime, McCallum, and Peterson (2014). This suggests that there is a relationship between relative vulnerability for rape and rape acknowledgment; groups who experience greater vulnerability are more likely to acknowledge rape.

\section{Minority stress theory}

Minority stress theory (Meyer, 1995, 2003) hypothesizes that the experiences of stress related to marginalization increase vulnerability for negative health outcomes, including sexual violence, among sexual minority people. The minority stress framework outlines risk factors for 
sexual violence that are unique to sexual minorities, such as experiences of discrimination or degree of outness, as well as protective factors, such as feelings of inclusion or connectedness to the LGBTQ community (Meyer, 2015). Empirical support for this theory in examining vulnerability for sexual violence is building. For example, experiences of discrimination mediate vulnerability for dating violence in bisexual young adults (Martin-Storey \& Fromme, 2017), perceived inclusion of LGBTQ people is related to lower rates of sexual violence on college campuses (Coulter \& Rankin, 2017), and individual feelings of connectedness to the LGBTQ community are related to lower individual vulnerability for violence (Murchison et al., 2016). Minority stress theory has been crucial to the development of LGB affirmative therapies and by incorporating the theory in this study we hope that our results can inform future psychotherapeutic work with sexual and gender minorities

Assessing minority stress variables in relation to bisexual and non-binary young people and their experiences of sexual violence may be of particular importance. Stereotypes regarding bisexuality include thinking bisexual people are hypersexual and are interested in having sex with everyone (Bostwick \& Hequembourg, 2014). Some young bisexual people have pointed to these stereotypes as ways in which people have justified sexually assaulting them (Flanders, Ross, Dobinson, \& Logie, 2017). If bisexual people receive the message that they do not have the right to refuse sex, this may also impact the frequency by which they identify coercive sexual encounters as sexual violence. Considering non-binary people, some people endorse the stereotype that non-binary people are confused or are attention-seeking (Nadal, Whitman, Davis, Erazo \& Davidoff, 2016), and as such should not be taken seriously, which could have important implications for sexual violence and acknowledgement. Thus, in studying sexual violence and 
rape acknowledgment in marginalized populations is it important to consider constructs specific to their experiences.

\section{Current Study}

The goal of the current study was to examine the prevalence of rape acknowledgment and associated mental health correlates in a sample of bisexual people using a minority stress framework. Specifically, we hypothesize that:

1. Rape acknowledgment will be greater in non-binary bisexual people than in cisgender people consistent with Anderson et al., (2017).

a. Due to lack of background literature, we will also conduct exploratory analyses to investigate the rates of rape acknowledgement between non-binary people and a) trans people, b) male participants (cis and trans inclusive) and female participants (cis and trans inclusive).

2. Lack of acknowledgment (i.e., unacknowledgment) will be associated with greater depressive and anxiety symptoms among non-binary participants, consistent with Littleton et al. (2009).

3. Rape acknowledgment will be associated with greater PTSD symptoms among nonbinary participants (per Littleton et al., 2009; Wilson \& Scarpa, 2015).

4. Greater outness and connection to the LGBTQ community will be positively associated with rape acknowledgment (Murchison et al., 2016), while greater internalized bisexual negativity will be associated with lack of acknowledgment among non-binary participants.

\section{Methods}


The data reported in this paper were from a larger mixed-methods project investigating the sexual victimization experiences and mental health of young bisexual people ages 18-25 (Flanders, C. E., Anderson, R. E., \& Tarasoff, L. A., in preparation). All study procedures were reviewed and approved by the Institutional Review Board of Mount Holyoke College.

\section{Participants}

A total of 245 individuals ages $18-25(M=22.23, S D=2.21)$ who identified their sexual orientation under the bisexual umbrella participated in the study. The majority of participants identified as bisexual ( $n=209,85.3 \%$ ), with the remainder of participants identifying with another plurisexual identity (i.e., an identity that describes attraction to more than one gender such as pansexual). Most participants ( $n=159 ; 65.2 \%)$ identified with a non-binary gender identity; in addition, 27 (11.1\%) identified as trans men, 4 (1.6\%) as cisgender men, 7 (2.9\%) as trans women, and 47 (19.3\%) as cisgender women. A total of 131 participants (53.5\%) identified as white, 31 (12.7\%) as Latinx, 23 (9.4\%) as Black, 18 (7.3\%) as American Indian or Alaskan Native, 15 (6.1\%) as Indian, 11 (4.5\%) as Cuban, 10 (4.1\%) as Puerto Rican, and 8 (3.3\%) as Mexican or Chicano. Overall, 119 participants (48.6\%) identified with a racial or ethnic minority identity. The majority of participants (136, 55.5\%) reported that their highest level of education was having attended some college, without yet earning an undergraduate degree.

Eligibility and recruitment. Participants had to be aged 18-25, identify as bisexual or as another plurisexual identity, and live in the U.S. or Canada. Participants were recruited through convenience sampling, predominantly through online social media, including Facebook and Twitter. Fliers were also posted in physical locations in Western Massachusetts and in Toronto, Ontario. The fliers stated that the researchers were looking for young bisexual people to 
participate in a study on sexual health, and that the study included questions regarding experiences of sexual violence.

\section{Procedure}

Participants accessed the study through a link included on the recruitment flier. Upon accessing the survey, participants were directed to an informed consent page. If they consented to participate, participants were routed to the survey. Participants received a \$15 Amazon gift card as an incentive. Participants completed the study questionnaires in the following fixed order: sexual violence history, bisexual identity, depressive symptoms, anxiety symptoms, PTSD symptoms, Connectedness to LGBTQ community, and then the Outness Inventory.

\section{Materials}

Sexual Experiences Survey - Short Form Victimization (SES-SFV). The SES-SFV assesses three forms of sexual violence: unwanted sexual contact (sexual victimization that does not involve any penetration, e.g., groping), verbal coercion (sexual victimization via verbal tactics), and rape (oral, anal, or vaginal penetration via alcohol/drug incapacitation, threats of force, or physical force) (Koss et al., 2007). The SES-SFV has between 5 to 7 behaviorally specific items designed to assess a history of sexual victimization. The number of items depends on the gender of the respondent. Each item begins with a stem describing a sexual behavior "someone put their penis into my genitals...." followed by five possible tactics (verbal criticism, verbal pressure, alcohol incapacitation, threats of physical force, physical force) that were used to coerce the behavior. After completing the behaviorally specific items, a final item assesses rape acknowledgment, “Have you ever been raped?” Participants who respond affirmatively to the behaviorally specific items of rape and affirmatively to the acknowledgment item are then coded as acknowledged survivors whereas participants who respond affirmatively to the 
behaviorally specific items but deny the acknowledgment item are coded as unacknowledged survivors. The SES-SFV has demonstrated validity and test-retest reliability in prior research with young adults (Anderson, Cahill, \& Delahanty, 2018a; Johnson, Murphy, \& Gidycz, 2017).

For the purposes of the current study, we modified the SES-SFV to be more inclusive and thus more appropriate for a sexual and gender minority population consistent with recommendations for inclusive research practice in violence (Hipp \& Cook, 2017). Specifically, we combined the questions regarding vaginal and anal acts. The altered items are presented in comparison to the original SES-SFV items in Table 1. The combining and rephrasing of these questions removed the need for participants to select whether the item was applicable by virtue of the appearance of their genitalia. Thus, we administered a total of 5 behaviorally specific items to assess sexual victimization history rather than the traditional 7 for cisgender women. Prior research has demonstrated that more inclusive and gender neutral item have similar or even improved psychometric properties compared to the original SES-SFV items (Anthony \& Cook, 2012). Given that we utilized the SES-SFV to compute prevalence and make categorical comparisons, we did not compute Cronbach’s alpha. Cronbach’s alpha is the recommend standard of reliability for latent constructs but is inappropriate for measures of behavioral experiences (Diamantopoulos, Riefler, \& Roth, 2008; Koss et al., 2007). In the case of sexual victimization, there is no latent construct within participants that would cause victimization.

Patient Health Questionnaire-9 (PHQ). The PHQ is a 9-item measure of depressive symptoms (Kroenke, Spitzer, \& Williams, 2001), that asks participants to reflect how frequently they have experienced certain symptoms over the past two weeks, such as "little interest or pleasure in doing things.” Responses are on a 4-point scale, ranging from 0 (not at all) to 3 (nearly every day). The measure is scored through summing all participant responses, thus totals 
range between 0-27, with zero indicating no depressive symptomatology. The Cronbach’s alpha for the PHQ among our current sample was 0.88. The PHQ-9 has demonstrated excellent reliability and validity in prior research (Kroenke, Spitzer, \& Williams, 2001).

Overall Anxiety Severity and Impairment Scale (OASIS). The OASIS is a 5-item measure of anxiety that asks participants to reflect on the frequency or severity of various symptoms over the past week, including "In the past week, how often have you felt anxious?” The response format is a 5-point scale ranging from $0-4$, and the measure is scored through summing participant responses. Total scores range from 0-20, with zero indicating no anxiety. Among the current sample, the Cronbach’s alpha score was 0.83. The OASIS has demonstrated good evidence of reliability and validity in past research (Campbell-Sills et al., 2009).

PTSD Checklist-Civilian Version (PCL-C). The PCL-C is a 17-item measure of PTSD symptoms (Weathers, Litz, Huska, \& Keane, 1994), that asks participants to identify how much they have been bothered by various symptoms over the past month, such as "Repeated, disturbing memories, thoughts, or images of a stressful experience from the past.” Participants respond on a 1 (not at all) to 5 (extremely) scale, and the measure is scored through summing participant responses for an overall severity score. Total scores range between 17-85, with a score of 17 indicating no PTSD symptoms and scores over 30 indicating likely clinical significance. The measure demonstrated high internal reliability with our sample, with Cronbach’s alpha value of 0.94. The PCL-C has demonstrated excellent evidence of reliability and validity in past research (Weathers et al., 1994).

Outness Inventory. The Outness Inventory is an 11-item measure that evaluates how open participants are about their sexual orientation (Mohr \& Fassinger, 2000). Participants report as to whether various people in their lives, such as their mother, siblings, and work peers, know 
about their sexual orientation and how frequently they talk about it, using a 7-point scale. Response options range from 1 (person definitely does not know about your sexual orientation status) to 7 (person definitely knows about your sexual orientation status, and it is openly talked $a b o u t)$. Responses are averaged for the three subscales, and then each subscale score is averaged together. The Cronbach's alpha score with the current sample was 0.90 . This questionnaire has demonstrated good reliability and validity in past research (Mohr \& Fassinger, 2000).

Connectedness to LGBTQ Community. The Connectedness to LGBT Community scale is an 8-item measure developed to assess how connected participants feel to their local LGBT community (Frost \& Meyer, 2012). Items include, “You feel you're a part of your area’s LGBT community." Participants respond on a 1 (strongly agree) to 4 (strongly disagree) scale. Items are reverse-scored and then averaged to calculate total scores. The measure demonstrated acceptable internal reliability with a Cronbach's alpha of 0.78 . This measure has demonstrated good evidence of validity and reliability in past research (Frost \& Meyer, 2012).

Bisexual Identity Inventory (BII) - Internalized binegativity subscale. The BII Internalized binegativity subscale consists of 5 items intended to assess internalized negative thoughts about bisexuality, such as “It's unfair that I am attracted to people of more than one gender." Participants respond on a 1 (strongly disagree) to 5 (strongly agree) scale, and total scores are generated through averaging participant responses. In the current sample, Cronbach's alpha was 0.71 . This questionnaire has demonstrated good evidence of reliability and validity in past research (Paul, Smith, Mohr, \& Ross, 2014).

\section{Results}

\section{Analytic Plan}


The amount of missing data was very limited, and as such, missing data were handled via listwise deletion in the analyses $(n=8 ; 3.37 \%)$. In our results section, we first report descriptive statistics regarding experience of sexual violence and rape acknowledgement, including all 245 participants. To test hypothesis one, we excluded any participants who did not report an experience of rape as assessed by the SES-SFV, and those who did not respond to the rape acknowledgement question, resulting in a sample of 202 participants. To test hypotheses 2-4, which focus on the experiences of rape acknowledgement among non-binary participants, we limited our sample to participants who identified as non-binary $(n=134)$.

Hypothesis 1. In comparing whether there is a relationship between gender identity and prevalence of rape acknowledgement, we fit a series of four separate logistic regression models to compare non-binary participants with four non-mutually exclusive gender groups: cisgender participants (including men and women), trans participants (including men and women), male participants (including cisgender and transgender), and female participants (including cisgender and transgender). The sociodemographic variables of age, race (categorized as whether participants identified as a person of color; POC), and formal education level (categorized as having obtained an undergraduate degree or higher or having accessed less education) were included as covariates in each logistic regression model. Given the multiple comparisons, we implemented the Bonferroni correction, which resulted in an alpha criterion of $p=0.0125$.

Hypotheses 2 and 3. We first assessed whether the above listed sociodemographic variables were associated with any of the mental health outcomes. Identifying as POC was associated with anxiety, and was included in this model. We fit a series of three linear regression models, one each for the outcomes (depression, anxiety, and PTSD symptoms) among participants who identified as non-binary. 
Hypothesis 4. To assess whether level of outness (about sexual orientation), connection to LGBTQ community, or internalized binegativity were associated with rape acknowledgement among non-binary participants, we fit a logistic regression model rape acknowledgment on minority stress variables among non-binary participants.

\section{Descriptive Results on Sexual Victimization}

Sexual victimization was very common among participants. Of the 245 total participants, 91.4\% of participants reported a sexual victimization experience of some type. Specifically, 89.8\% reported unwanted sexual contact, 80.8\% reported verbal coercion, and $82.4 \%$ reported rape. Among the 159 participants who identified with a non-binary gender identity, a total of 147 (92.5\%) reported unwanted contact, 143 (89.9\%) reported verbal coercion, and 141 (88.7\%) reported rape. For comparison, 32 (94.1\%) of trans participants and 28 (54.9\%) of cisgender participants reported experiencing rape.

Among the 141 non-binary participants who experienced rape, a total of 134 responded to the SES-SFV acknowledgment item. Of these 134 participants, 27 reported they had never been raped (i.e., unacknowledged survivors - 20.1\%), whereas 107 indicated they had (acknowledged survivors $-79.9 \%)$. These descriptive data, plus the data from trans men and women as well as cisgender men and women are reported in Table 1.

\section{Prevalence of Rape Acknowledgment}

There was no statistically significant relationship between gender identity and rape acknowledgement when comparing non-binary participants to cisgender participants, or to female-identifying participants. However, there was a statistically significant difference between non-binary and trans participants $[b=3.39$, Standard Error $(\mathrm{SE})=0.62, p<0.001$; odds ratio 98.75\% confidence interval (OR 98.75\% CI): $29.76(6.39,138.95)$. Due to the small sample of 
trans participants, the wide CI suggests an imprecise OR point estimate, however the finding still indicates that non-binary participants were more likely to endorse rape acknowledgement than were trans participants. There was also a statistically significant difference in rape acknowledgement between non-binary participants and male-identifying participants $[b=3.65$, SE, $=0.69, p<0.001$; OR 98.75\% CI: 38.63 (6.87, 217.23)]. These results again indicate that non-binary participants are more likely to acknowledge rape experiences as rape in contrast to male participants. Notably, there was significant overlap in participants who identified as trans and participants who identified as male due to the low number of trans women participants, which may contribute to similar point estimates for these two groups in comparison to nonbinary participants. In each of the four regression models, participants who identified as POC reported significantly greater prevalence of rape acknowledgement. Results from these models are presented in Table 3.

\section{Associations between Rape Acknowledgment and Mental Health Outcomes}

Depression. Among non-binary participants, rape acknowledgement was significantly related to depressive symptoms. Acknowledgement was associated with a 7.75 unit increase in depressive symptom scores $(b=7.75$, S.E. $=1.00, p<0.001)$. The adjusted $R^{2}$ score indicated that approximately $30.9 \%$ of the variance in depressive symptom scores could be accounted for by whether or not individuals acknowledged they had been raped.

Anxiety. Rape acknowledgement was significantly associated with a 4.22 unit increase in anxiety symptom score $(b=4.22$, S.E. $=0.74, p<0.001)$, and identifying as POC was also a significant predictor $(b=1.82$, S.E. $=0.65, p=0.006)$. The adjusted $R^{2}$ indicated that approximately 39\% of the variance in reported anxiety symptoms can be explained by rape acknowledgment and identifying as POC. 
PTSD. Rape acknowledgement was also significantly associated of PTSD symptoms. Specifically, rape acknowledgement was significantly associated with a 14.48 unit increase in PTSD symptom scores (S.E. $=1.805, p<.001)$. Participants who acknowledged they had been raped reported an average score of $52.81($ S.D. $=9.50)$, which is above the PCL-5 clinically significant symptom cut-off of 30-35 (National Center for PTSD, 2012). The model's adjusted $R^{2}$ indicated that $27.7 \%$ of the variance in reported PTSD symptoms can be explained by rape acknowledgment.

\section{Associations with Sexual and Gender Minority Specific Risk and Protective Factors}

Connection to LGBTQ community and internalized binegativity were not significant predictors, whereas level of outness was $(b=2.15$, S.E. $=0.38, p<.001)$. Outness was associated with an odds ratio of $8.62(95 \%$ C.I. $=4.09,18.22)$, indicating that participants who were more out acknowledged their rape by a factor of 8 .

\section{Discussion}

People who identify as SGM experience greater vulnerability for sexual violence; yet, little is known about their experiences of sexual violence nor how their experiences of coping and recovery may differ (Rothman et al., 2011; Stotzer, 2009). For those who embody both of these minority identities, such as people who identify as bisexual and non-binary, vulnerability may be compounded. Indeed, the prevalence of rape was $82.4 \%$ in this sample of racially diverse bisexual people.

This is one of the first studies to examine rape acknowledgment and mental health correlates in people who identify as bisexual or non-binary. Consistent with Hypothesis 1, rape acknowledgment was greater among non-binary participants compared to trans participants of all genders, as well as male participants. The prevalence of rape and corresponding rape 
acknowledgment was extraordinarily high compared to prior research: $79.9 \%$ of non-binary participants acknowledged their rape. The prevalence of acknowledgment in this study was twice as high compared to cisgender college women (Wilson \& Miller, 2016), nearly four times that of cisgender community men (Artime et al., 2014) and sexual minority college men (Anderson et al., 2017), and 20 times higher than heterosexual cisgender college men (Anderson et al., 2017). This finding is consistent with our hypothesis that increased vulnerability for sexual violence is associated with increased prevalence of acknowledgment. In addition, we suggest that bisexual non-binary people may also be less likely to hold certain attitudes that are associated with lower acknowledgment, such as strict ideas about gender norms and rape myth acceptance (Schulze \& Koon-Magnin, 2017; Wilson, Miller, Leheney, Ballman, \& Scarpa, 2017; Wilson et al., 2017). We may also have uncovered higher prevalence of rape and rape acknowledgment by using a more inclusive assessment of sexual violence history than prior studies. However, our recruitment strategy may have artificially inflated prevalence of acknowledgment; flyers specifically described the topic of sexual violence. Acknowledged survivors tend to have greater rape empathy (Osman, 2016) and have experienced more violent assaults (Bondurant, 2001); thus, our recruitment strategy may have been more likely to appeal to acknowledged survivors who may have been more likely to volunteer to participate.

We also found that acknowledgment was associated with mental health symptoms, specifically depressive, anxiety, and PTSD symptoms (Hypotheses 2 and 3). These findings are somewhat inconsistent with hypotheses - unacknowledgment was associated with depressive and anxiety symptoms in prior research. However, Wilson et al. (2017) found that the relationship between rape acknowledgment and depression symptoms was moderated by rape myth acceptance. Given the lower endorsement of these attitudes by sexual minorities (Worthen, 
2017), perhaps these findings are not surprising, and indicate that recovery after rape is different for SGM people. It may also be that the high levels of rape acknowledgment in our sample limited variability for this comparison.

Notably, the level of PTSD symptoms among non-binary acknowledged survivors in this study were within clinical range $(\mathrm{M}=52.68)$ indicating unmet mental health needs. This finding strongly suggests there is a need for trauma-focused therapies for SGM rape survivors. We also found that a minority stress theory variable was predictive of acknowledgment; specifically, outness (Hypothesis 4). It is interesting that outness was associated with increased rates of acknowledgment; perhaps those who have a higher rate of disclosure of their sexual orientation are more able to also grapple with labeling their sexual violence experiences because they have more sources of social support.

Inconsistent with hypotheses, we did not find a relationship between acknowledgment and internalized binegativity or connectedness to the LGBTQ community. Considering binegativity, it could be that the subscale we used, which largely depicts negative feelings about being bisexual, might not relate as directly to people’s experiences of rape acknowledgement. Related to the lack of relationship between LGBTQ community connection and rape acknowledgement, this may in part be due to the disconnect and marginalization that many bisexual and non-binary people report experiencing in relation to the broader LGBTQ community (Boyd Farmer \& Byrd, 2015; Roberts, Horne, \& Hoyte, 2015). Biphobia and transphobia in LGBTQ community can prevent bisexual and non-binary people from accessing support from community, and as such connection to LGBTQ community may not be a significant factor for rape acknowledgement among these groups. Since many of our participants were also POC, and POC experience racism from others within the LGBTQ community 
(Ghabrial, 2017), this may further complicate access to support from the LGBTQ community. Future research should consider the unique needs and supports of various SGM populations as well as how individuals' identities (i.e., sexual orientation, gender identity, race) and inequalities (i.e., biphobia, transphobia, racism) intersect (Ghabrial, 2017; Bowleg, 2008) to shape their outness, LGBTQ community connectedness, feelings about being bisexual, and health and wellbeing. There may also be unique stereotypes and beliefs about POC, particularly women of color (e.g., Black women as the Jezebel), that may shape how POC perceive and experience sexual violence (Donovan \& Williams, 2002).

\section{Limitations and Future Research}

While our study adds to the limited literature on sexual violence among bisexual and nonbinary populations, our sample was exclusively people who identified under the bisexual umbrella. It is difficult to quantify the risk that comes from the intersecting marginalization of bisexual and non-binary identities. We also had very small groups of binary trans and cisgender participants, meaning our comparisons of rape acknowledgement between groups may be less reliable. Further, we were unable to test how attitudinal factors like rape myth acceptance and gender role norms might mediate or moderate the relationship between rape acknowledgment and mental health outcomes. Future research should include mental health process variables such as coping, disclosure, and social support. Further, we concur with Artime and colleagues (2014) that masculinity may be a particularly important construct to include for men and non-binary participants and should also be examined in future work.

We strongly recommend further research on sexual violence in SGM populations. We found that the prevalence of verbal coercion and rape were nearly the same in this sample; research with cisgender heterosexual populations usually finds that verbal coercion is much more 
common than rape (Black et al., 2011). This finding suggests that the sexual violence experiences of bisexual and non-binary people may be radically different and much more severe than the sexual violence experiences of heterosexual and cisgender people. We also had a small number $(n=5)$ of participants who responded affirmatively to the acknowledgment item yet endorsed verbal coercion items and not any rape items. This could be due to one of two explanations: either this population conceptualizes what "rape” is differently that the researchers who created sexual violence research tools or our assessment of sexual victimization history did not capture their experience of rape. At this point, we consider these hypotheses of equal probative value. Because sexual minorities are less likely to endorse rape myths (Worthen, 2017), our population may have had a broader view of what rape is, misaligned with research definitions. It is important to consider how our participants may use these terms and how our research methods may invalidate their experiences. For example, being verbally pressured to have sex is considered verbal coercion by researchers but may be perceived differently by participants who then respond affirmatively to the acknowledgment item. It is also possible that the SES-SFV, even when modified to maximize inclusivity, did not capture all our participants' victimization experiences. For example, SGM participants are uniquely susceptible to threats of being outed, which can jeopardize housing and employment security. At present, a verbal threat such as "have sex with me or I will evict you" is not captured by the SES-SFV except perhaps under the phrase “physical harm.” Anderson, Cahill, and Delahanty (2018b) highlighted large gaps between cases detected by the SES-SFV and another measure of sexual violence victimization; other researchers have also documented lower than expected correlations between the other versions of the Sexual Experiences Survey and alternative measures of sexual victimization (French, Suh, \& Arterberry, 2017). This suggests systematic imprecision in how 
sexual violence is measured that may be likely more pronounced for less well-studied populations such as gender and sexual minorities.

\section{Clinical and Policy Implications}

Our findings suggest that the unmet mental health needs of bisexual non-binary people may be high, particularly as they relate to trauma recovery. We strongly encourage approaches that are inclusive and affirmative for SGM people, such as the transdiagnostic minority stress approach, which incorporates minority stress theory into cognitive-behavioral therapies for sexual minorities (Burton, Wang, \& Pachankis, 2017; Pachankis, Hatzenbuehler, Rendina, Safren, \& Parsons, 2015). We suggest individuals and organizations seek out or provide training and consultation in these models. Further, these approaches should be sensitive to how gender and sexual minority POC experience and recover from sexual violence, in particular as access to social support may differ in comparison to white LGBTQ people. This work also suggests that continued support for grant funding and scientific programs that support reducing sexual orientation and gender minority related health disparities are critical for promoting the health of the LGBTQ community (Hudson \& Collins, 2017).

\section{Conclusions}

This study documented extraordinarily high prevalence of rape and rape acknowledgment among non-binary bisexual people, underscoring the increased vulnerability of people who are sexual and gender minorities for experiencing sexual violence. We found that rape acknowledgment was associated of increased anxiety, depression, and PTSD symptoms, and that outness was associated with rape acknowledgment. These findings underscore the importance of investigating sexual violence in sexual and gender minority populations using a minority stress framework. 


\section{References}

Anderson, R. E., Cahill, S. P., \& Delahanty, D. L. (2018a). The Psychometric Properties of the Sexual Experiences Survey-Short Form Victimization (SES-SFV) and Characteristics of Sexual Victimization Experiences in College Men. Psychology of Men and Masculinity, 19(1), 25-34. doi.org/10.1037/men0000073

Anderson, R. E., Cahill, S. P., \& Delahanty, D. L. (2018b). Discordance between the Sexual Experiences Surveys-Short Forms and the Revised Conflict Tactics Scales in college men. Psychology of Violence. doi.org/10.1037/vio0000199

Anderson, R. E., Wandrey, R. L., Klossner, S. C., Cahill, S. P., \& Delahanty, D. L. (2017). Sexual Minority Status \& Interpersonal Victimization in College Men. Psychology of Sexual Orientation and Gender Diversity, 4(1), 130-136. doi.org/10.1037/sgd0000204

Anthony, E. R., \& Cook, S. L. (2012). Assessing the impact of gender-neutral language on disclosure of sexual violence. Psychology of Violence, 2(3), 297-307. doi.org/10.1037/a0028562

Artime, T. M., McCallum, E. B., \& Peterson, Z. D. (2014). Men’s acknowledgment of their sexual victimization experiences. Psychology of Men \& Masculinity, 15(3), 313-323.

Balsam, K. F., Rothblum, E. D., \& Beauchaine, T. P. (2005). Victimization over the life span: a comparison of lesbian, gay, bisexual, and heterosexual siblings. Journal of Consulting and Clinical Psychology, 73(3), 477-487. doi.org/10.1037/0022-006X.73.3.477

Basile, K. C., Smith, S., Breiding, M. J., Black, M. C., \& Mahendra, R. (2014). Sexual Violence Surveillance: Uniform Definitions and Recommended Data Elements, Version 2.0. Atlanta, GA. Retrieved from www.cdc.gov/violenceprevention/pdf/sv_surveillance_definitionsl2009-a.pdf 
Bauer, G. R., \& Hammond, R. (2015). Toward a broader conceptualization of trans women's sexual health. The Canadian Journal of Human Sexuality, 24(1), 1-11.

Black, M. C., Basile, K. C., Breiding, M. J., Smith, S., Walters, M. L., Merrick, M., ... Stevens, M. (2011). The National Intimate Partner and Sexual Violence Survey (NISVS): 2010 Summary Report. Atlanta, GA, USA.

Bondurant, B. (2001). University Women’s Acknowledgment of Rape. Violence Against Women, 7(3), 294-314. doi.org/10.1177/1077801201007003004

Bostwick, W., \& Hequembourg, A. (2014). “Just a little hint”: bisexual-specific microaggressions and their connection to epistemic injustices. Culture, Health \& Sexuality, 16(5), 488-503. https://doi.org/10.1080/13691058.2014.889754

Botta, R. A., \& Pingree, S. (1997). Interpersonal communication and rape: Women acknowledge their assaults. Journal of Health Communication, 2(3), 197-212. hdoi.org/10.1080/108107397127752

Bowleg, L. (2008). When Black + lesbian + woman $\neq$ Black lesbian woman: The methodological challenges of qualitative and quantitative intersectionality research. Sex Roles, 59, 312-325. Boyd Farmer, L., \& Byrd, R. (2015). Genderism in the LGBTQQIA community: an interpretive phenomenological analysis. Journal of LGBT Issues in Counseling, 9(4), 288-310.

Breslau, N., Kessler, R. C., Chilcoat, H. D., Schultz, L. R., Davis, G. C., \& Andreski, P. (1998). Trauma and posttraumatic stress disorder in the community: The 1996 Detroit Area Survey of Trauma. Archives of General Psychiatry, 55(7), 626-632. doi.org/10.1001/archpsyc.55.7.626

Burton, C. L., Wang, K., \& Pachankis, J. E. (2017, June 1). Psychotherapy for the Spectrum of Sexual Minority Stress: Application and Technique of the ESTEEM Treatment Model. 
Cognitive and Behavioral Practice. doi.org/10.1016/j.cbpra.2017.05.001

Clements, C. M., \& Ogle, R. L. (2009). Does Acknowledgment as an Assault Victim Impact Postassault Psychological Symptoms and Coping? Journal of Interpersonal Violence, 24(10), 1595-1614. doi.org/10.1177/0886260509331486

Coulter, R. W. S., \& Rankin, S. R. (2017). College Sexual Assault and Campus Climate for Sexual- and Gender-Minority Undergraduate Students. Journal of Interpersonal Violence, 088626051769687. doi.org/10.1177/0886260517696870

Diamantopoulos, A., Riefler, P., \& Roth, K. P. (2008). Advancing formative measurement models. Journal of Business Research, 61(12), 1203-1218. doi.org/10.1016/j.jbusres.2008.01.009

Donovan, R., \& Williams, M. (2002) Living at the Intersection, Women \& Therapy, 25:3-4, 95105, doi: $\underline{\text { 10.1300/J015v25n03_07 }}$

Flanders, C., Anderson, R. E., \& Tarasoff, L. A. (in preparation). Young bisexual people’s experiences of sexual violence: A Mixed methods study.

Flanders, C., Anderson, R. E., Tarasoff, L. A., \& Robinson, M., (2019) Bisexual stigma, sexual violence, and sexual health among bisexual and other plurisexual women: A Cross-sectional survey study. The Journal of Sex Research. 1-13. https://doi.org/10.1080/00224499.2018.1563042

French, B. H., Suh, H. N., \& Arterberry, B. (2017). Exploratory Factor Analysis and Psychometric Properties of the Sexual Coercion Inventory. The Journal of Sex Research, 54(8), 962-970. doi.org/10.1080/00224499.2016.1235129

Ghabrial, M. A. (2017). "Trying to figure out where we belong": Narratives of racialized sexual minorities on community, identity, discrimination, and health. Sexuality Research and 
Social Policy, 14(1), 42-55.

Griner, S. B., Vamos, C. A., Thompson, E. L., Logan, R., Vázquez-Otero, C., \& Daley, E. M. (2017). The Intersection of Gender Identity and Violence: Victimization Experienced by Transgender College Students. Journal of Interpersonal Violence, 088626051772374. doi.org/10.1177/0886260517723743

Hammond, C. B., \& Calhoun, K. S. (2007). Labeling of Abuse Experiences and Rates of Victimization. Psychology of Women Quarterly, 31(4), 371-380.

Hipp, T. N., \& Cook, S. L. (2017). Rape and sexual assault on campus, in diverse populations, and in the spotlight. In C. M. Renzetti, J. L. Edleson, \& R. K. Bergen (Eds.), Sourcebook on Violence Against Women (3rd ed., pp. 85-101). Thousand Oaks, CA, USA: SAGE Publications.

Hudson, K. L., \& Collins, F. S. (2017). The 21st Century Cures Act - A View from the NIH. New England Journal of Medicine, 376(2), 111-113. doi.org/10.1056/NEJMp1615745

Johnson, S. M., Murphy, M. J., \& Gidycz, C. A. (2017). Reliability and validity of the Sexual Experiences Survey - Short Forms victimization and perpetration. Violence and Victims, 32(1), 78-92. doi.org/10.1891/0886-6708.VV-D-15-00110

Koss, M. P., Abbey, A., Campbell, R., Cook, S., Norris, J., Testa, M., ... White, J. (2007). Revising the SES: A Collaborative process to improve assessment of sexual aggression and victimization. Psychology of Women Quarterly, 31(4), 357-370. doi.org/10.1111/j.14716402.2007.00385.x

LeMaire, K. L., Oswald, D. L., \& Russell, B. L. (2016). Labeling Sexual Victimization Experiences: The Role of Sexism, Rape Myth Acceptance, and Tolerance for Sexual Harassment. Violence and Victims, 31(2), 332-346. doi.org/10.1891/0886-6708.VV-D-13- 
00148

Littleton, H., Axsom, D., \& Grills-Taquechel, A. (2009). Sexual assault victims’ acknowledgment status and revictimization risk. Psychology of Women Quarterly, 33(1), 34-42. doi.org/10.1111/j.1471-6402.2008.01472.x

Littleton, H., Breitkopf, C. R., \& Berenson, A. (2008). Beyond the Campus: Unacknowledged Rape Among Low-Income Women. Violence Against Women, 14 VN-r(3), 269-286.

Littleton, H., \& Henderson, C. E. (2009). If she is not a victim, does that mean she was not traumatized?: Evaluation of predictors of PTSD symptomatology among college rape victims. Violence Against Women, 15(2), 148-167. doi.org/10.1177/1077801208329386

Littleton, H. L., Axsom, D., Breitkopf, C. R., \& Berenson, A. (2006). Rape Acknowledgment and Postassault Experiences: How Acknowledgment Status Relates to Disclosure, Coping, Worldview, and Reactions Received From Others. Violence and Victims, 21(6), 761-778. doi.org/10.1891/vv-v21i6a006

Littleton, H. L., Rhatigan, D. L., \& Axsom, D. (2007). Unacknowledged rape: How much do we know about the hidden rape victim? Journal of Aggression, Maltreatment \& Trauma, 14(4), 57-74. doi.org/10.1300/J146v14n04_04

Martin-Storey, A., \& Fromme, K. (2017). Mediating Factors Explaining the Association Between Sexual Minority Status and Dating Violence. Journal of Interpersonal Violence, 088626051772697. doi.org/10.1177/0886260517726971

Meyer, I. H. (1995). Minority Stress and Mental Health in Gay Men. Journal of Health and Social Behavior, 36(1), 38. doi.org/10.2307/2137286 
Meyer, I. H. (2003). Prejudice, Social Stress, and Mental Health in Lesbian, Gay, and Bisexual Populations: Conceptual Issues and Research Evidence. Psychological Bulletin, 129(5), 674-697. http://doi.org/10.1037/0033-2909.129.5.674

Meyer, I. H. (2015). Resilience in the Study of Minority Stress and Health of Sexual and Gender Minorities. Psychology of Sexual Orientation and Gender Diversity, 2(3), 209-213. doi.org/10.1037/sgd0000132

Murchison, G. R., Boyd, M. A., \& Pachankis, J. E. (2016). Minority Stress and the Risk of Unwanted Sexual Experiences in LGBQ Undergraduates. Sex Roles, 1-18. doi.org/10.1007/s11199-016-0710-2

Nadal, K. L., Whitman, C. N., Davis, L. S., Erazo, T., \& Davidoff, K. C. (2016). Microaggressions Toward Lesbian, Gay, Bisexual, Transgender, Queer, and Genderqueer People: A Review of the Literature. The Journal of Sex Research, 53(4-5), 488-508. https://doi.org/10.1080/00224499.2016.1142495

National Center for PTSD. (2012). Using the PTSD Checklist (PCL). Retrieved April 27, 2018, from sph.umd.edu/sites/default/files/files/PTSDChecklistScoring.pdf

Osman, S. L. (2016). Predicting Rape Victim Empathy Based on Rape Victimization and Acknowledgment Labeling. Violence against Women, 22(7), 767-779. doi.org/10.1177/1077801215610864

Pachankis, J. E., Cochran, S. D., \& Mays, V. M. (2015). The mental health of sexual minority adults in and out of the closet: A population-based study. Journal of Consulting and Clinical Psychology, 83(5), 890.

Pachankis, J. E., Hatzenbuehler, M. L., Rendina, H. J., Safren, S. A., \& Parsons, J. T. (2015). 
LGB-affirmative cognitive-behavioral therapy for young adult gay and bisexual men: A randomized controlled trial of a transdiagnostic minority stress approach. Journal of Consulting and Clinical Psychology, 83(5), 875-889. doi.org/10.1037/ccp0000037

Pepping, C. A., Lyons, A., \& Morris, E. M. J. (2018). Affirmative LGBT psychotherapy: Outcomes of a therapist training protocol. Psychotherapy, 55(1), 52-62. doi.org/10.1037/pst0000149

Roberts, T. S., Horne, S. G., \& Hoyt, W. T. (2015). Between a gay and a straight place: bisexual individuals' experiences with monosexism. Journal of Bisexuality, 15(4), 554-569.

Rothman, E. F., Exner, D., \& Baughman, A. L. (2011). The Prevalence of Sexual Assault Against People Who Identify as Gay, Lesbian, or Bisexual in the United States: A Systematic Review. Trauma, Violence, \& Abuse, 12(2), 55-66.

Schulze, C., \& Koon-Magnin, S. (2017). Gender, Sexual Orientation, and Rape Myth Acceptance: Preliminary Findings From a Sample of Primarily LGBQ-Identified Survey Respondents. Violence and Victims, 32(1), 159-180.

Sigurvinsdottir, R., Ullman, S. E. (2015). The role of sexual orientation in the victimization and recovery of sexual assault surviviors. Violence and Victims, 30(4), 636-648.

Soler-Baillo, J. M., Marx, B. P., \& Sloan, D. M. (2005). The psychophysiological correlates of risk recognition among victims and non-victims of sexual assault. Behaviour Research and Therapy, 43(2), 169-181. doi.org/10.1016/j.brat.2004.01.004

Stotzer, R. L. (2009). Violence against transgender people: A review of United States data. Aggression and Violent Behavior, 14(3), 170-179. doi.org/httpdx.doi.org/10.1016/j.avb.2009.01.006

Walters, M. L., Chen, J., \& Breiding, M. J. (2013). The National Intimate Partner and Sexual 
Violence Survey (NISVS): 2010 findings on victimization by sexual orientation. Atlanta, GA, USA.

Wilson, L. C., \& Miller, K. E. (2016). Meta-Analysis of the Prevalence of Unacknowledged Rape. Trauma, Violence \& Abuse, 17(2), 149-159. doi.org/10.1177/1524838015576391

Wilson, L. C., Miller, K. E., Leheney, E. K., Ballman, A. D., \& Scarpa, A. (2017). Examining the Psychological Effect of Rape Acknowledgment: The Interaction of Acknowledgment Status and Ambivalent Sexism. Journal of Clinical Psychology, 73(7), 864-878.

Wilson, L. C., Newins, A. R., \& White, S. W. (2017). The impact of rape acknowledgment on survivor outcomes: The moderating effects of rape myth acceptance. Journal of Clinical Psychology. doi.org/10.1002/jclp.22556

Wilson, L. C., \& Scarpa, A. (2015). Unacknowledged Rape: The Influences of Child Sexual Abuse and Personality Traits. Journal of Child Sexual Abuse, 24(8), 975-990.

Wilson, L. C., \& Scarpa, A. (2017). The unique associations between rape acknowledgment and the DSM-5 PTSD symptom clusters. Psychiatry Research, 257, 290-295.

Worthen, M. G. F. (2017). Rape Myth Acceptance Among Lesbian, Gay, Bisexual, and Mostly Heterosexual College Students. Journal of Interpersonal Violence, 088626051773328. 
Table 1.

Comparison of SES-SFV standardized and SES-SFV items as modified for this study

\section{SES-SFV item}

3: A man put his penis into my vagina, or someone inserted fingers or objects without my consent by...

6: Even though it didn't happen, a man TRIED to put his penis into my vagina, or someone tried to stick in fingers or objects without my consent by
Someone put their penis into my genitals or

butt, or someone inserted fingers or objects without my consent by...

Even though it did not happen, a someone TRIED to put their penis into my genitals or butt, or someone tried to stick in fingers or objects without my consent by

Note. SES-SFV = Sexual Experience Survey - Short Form Victimization. Underlines indicate altered text.

Table 2

Experience of non-consensual oral, genital, or anal sex and rape acknowledgement across gender identity $(N=245)$

Gender Identity $\quad$ Tactic $\quad$ N, (\%) Reporting $\quad$ N, (\%) Acknowledged Rape

$\begin{array}{llll}\text { Non-binary } & \text { Unwanted contact } & 147(92.5) & \\ & \text { Verbal coercion } & 143(89.9) & 107(79.9) \\ \text { Trans men } & \text { Rape } & 141(88.7) & \\ & \text { Unwanted contact } & 27(100) & 2(8.0) \\ \text { Trans women } & \text { Verbal coercion } & 26(96.3) & \\ & \text { Rape } & 25(92.6) & 3(42.9) \\ \text { Cis men } & \text { Unwanted contact } & 7(100) & \\ & \text { Verbal coercion } & 7(100) & 3(100) \\ \text { Cis women } & \text { Rape } & 7(100) & \\ & \text { Unwanted contact } & 3(75.0) & 16(64)\end{array}$

Note. The categories reported relate to the Sexual Experiences Scale - Short Form Victimization, where unwanted contact refers to indicating experience of unwanted sexual contact such as being groped, verbal coercion indicates someone used verbal tactics to coerce the participant into nonconsensual sex, and rape victimization via use or threat of physical force or incapacitation through alcohol or drugs. The final column reports the percentage of people who reported they had been raped relative to the number of people who endorsed one of the SES-SFV rape items. 
Table 3

Multivariable logistic regression models comparing rape acknowledgement rates between non-binary participants and other gender groups.

Variables

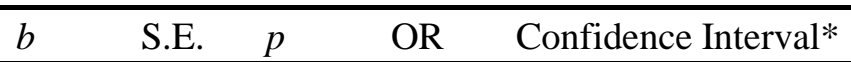

Model 1: Non-binary compared to trans participants, Nagelkerke $R^{2}=0.49$

$\begin{array}{llllll}\text { Gender (trans as referent) } & 3.39 & 0.62 & <.001 & 29.76 & 6.39,138.95 \\ \text { Identify as POC } & 2.39 & 0.49 & <.001 & 10.88 & 3.18,37.25 \\ \text { Education } & 0.71 & 0.75 & .341 & 2.04 & 0.31,13.25 \\ \text { Age } & 0.04 & 0.09 & .659 & 1.04 & 0.84,1.29\end{array}$

Model 2: Non-binary comparted to cis participants, Nagelkerke $R^{2}=0.39$

$\begin{array}{llllll}\text { Gender (cis as referent) } & -1.09 & 0.61 & .074 & 0.34 & 0.07,1.55 \\ \text { Identify as POC } & 3.15 & 0.57 & <.001 & 23.28 & 5.58,97.13 \\ \text { Education } & -0.13 & 0.63 & .841 & 0.88 & 0.19,4.21 \\ \text { Age } & 0.09 & 0.11 & .411 & 1.09 & 0.83,1.43\end{array}$

Model 3: Non-binary compared to female participants, Nagelkerke $R^{2}=0.30$

$\begin{array}{llllll}\text { Gender (female as referent) } & -0.09 & 0.52 & .856 & 0.91 & 0.25,3.34 \\ \text { Identify as POC } & 2.45 & 0.48 & <.001 & 11.64 & 3.52,38.47 \\ \text { Education } & 0.45 & 0.59 & .438 & 1.58 & 0.37,6.80 \\ \text { Age } & 0.02 & 0.08 & .849 & 1.02 & 0.83,1.24\end{array}$

Model 4: Non-binary compared to male participants, Nagelkerke $R^{2}=0.51$

\begin{tabular}{llllll} 
Gender (male as referent) & 3.65 & 0.69 & $<.001$ & 38.63 & $6.87,217.23$ \\
Identify as POC & 2.66 & 0.53 & $<.001$ & 14.29 & $3.78,54.02$ \\
Education & 0.15 & 0.74 & .845 & 1.16 & $0.18,7.41$ \\
Age & 0.14 & 0.13 & .263 & 1.15 & $0.84,1.58$ \\
\hline
\end{tabular}

Note: For the Identify as POC variable, white people are the referent group, compared to people of color. For the education variable, less education than a Bachelor's degree is the referent, compared to people with a Bachelor's degree or higher. *Confidence interval set to $98.75 \%$ to account for Bonferroni Correction. 